OAK RIDGE

NATIONAL LABORATORY

FOR THE DEPARTMENT OF ENERGY

\title{
Optimizing River Flows for Salmon and Energy
}

\section{October 2012}

Prepared by

Henriette I. Jager

Rocio Martinez

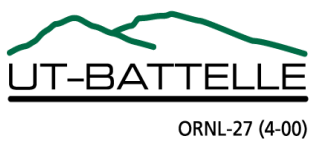




\section{DOCUMENT AVAILABILITY}

Reports produced after January 1, 1996, are generally available free via the U.S. Department of Energy (DOE) Information Bridge.

Web site http://www.osti.gov/bridge

Reports produced before January 1,1996, may be purchased by members of the public from the following source.

National Technical Information Service

5285 Port Royal Road

Springfield, VA 22161

Telephone 703-605-6000 (1-800-553-6847)

TDD 703-487-4639

Fax 703-605-6900

E-mailinfo@ntis.gov

Web site http://www.ntis.gov/support/ordernowabout.htm

Reports are available to DOE employees, DOE contractors, Energy Technology Data Exchange (ETDE) representatives, and International Nuclear Information System (INIS) representatives from the following source.

Office of Scientific and Technical Information

P.O. Box 62

Oak Ridge, TN 37831

Telephone 865-576-8401

Fax 865-576-5728

E-mail reports@osti.gov

Web site http://www.osti.gov/contact.html

This report was prepared as an account of work sponsored by an agency of the United States Government. Neither the United States Government nor any agency thereof, nor any of their employees, makes any warranty, express or implied, or assumes any legal liability or responsibility for the accuracy, completeness, or usefulness of any information, apparatus, product, or process disclosed, or represents that its use would not infringe privately owned rights. Reference herein to any specific commercial product, process, or service by trade name, trademark, manufacturer, or otherwise, does not necessarily constitute or imply its endorsement, recommendation, or favoring by the United States Government or any agency thereof. The views and opinions of authors expressed herein do not necessarily state or reflect those of the United States Government or any agency thereof. 


\title{
OPTIMIZING RIVER FLOWS FOR SALMON AND ENERGY
}

\author{
Henriette I. Jager \\ Rocio Martinez \\ Brennan Smith
}

October 2012

\author{
Prepared by \\ OAK RIDGE NATIONAL LABORATORY \\ Oak Ridge, Tennessee 37831-6283 \\ managed by \\ UT-Battelle, LLC \\ for the \\ U.S. DEPARTMENT OF ENERGY \\ Under contract DE-AC05-00OR22725
}




\section{CONTENTS}

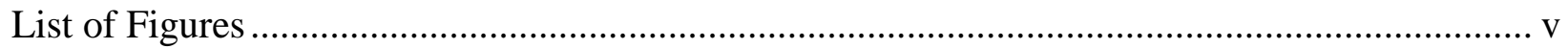

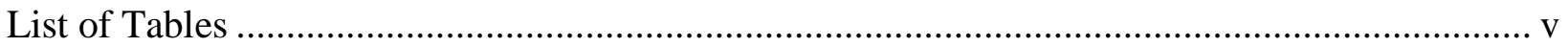

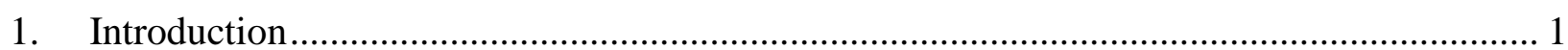

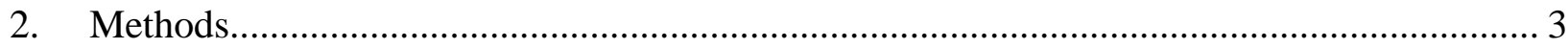

2.1 CLIMATE DRIVERS AND PHYSICAL HABITAT .............................................. 3

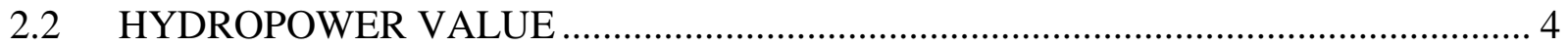

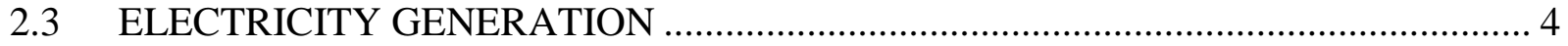

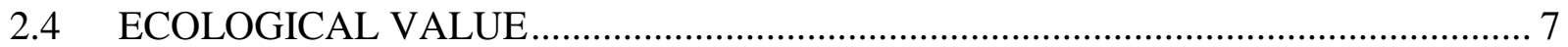

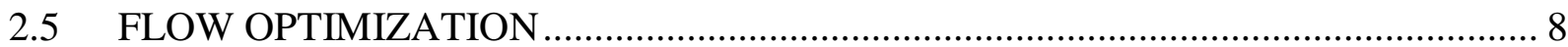

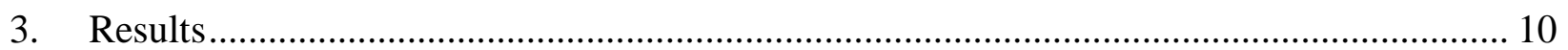

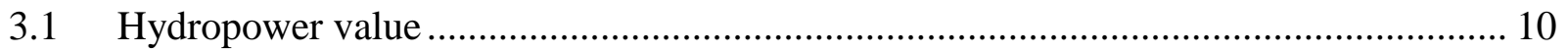

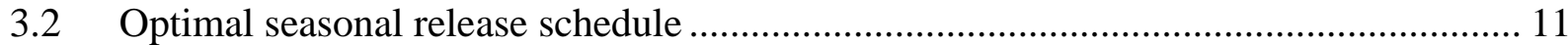

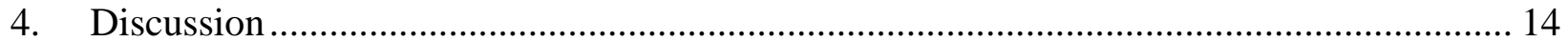

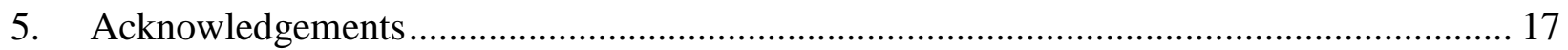

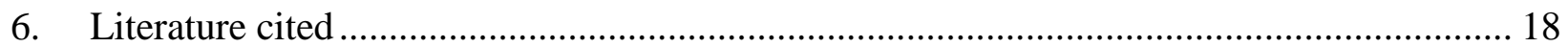




\section{List of Figures}

Figure 1. Two relationships that describe seasonal influences on power generation: (top) turbine efficiency, power generation vs. flow; (bottom) predictable seasonal variation in head, as determined by reservoir elevation (Source: Stillwater Sciences 2011).

Figure 2. Optimal flow regimes to meet the salmon production objective. These flow regimes allocated total annual flows of $0.632 \mathrm{~km}^{3}$ and were obtained using a single-objective method, with a weight of one assigned to the salmon objective. Results are shown for three different initial seeds, two of which overlap substantially.

Figure 3. Seasonal patterns in relative marginal energy value, based on fitted model.

Figure 4. Frontier of non-dominated solutions showing the shift in seasonal flow regimes favoring modelsimulated salmon production and those favoring energy value. Three examples of optimal flow regimes are illustrated above their positions along the frontier.

Figure 5. Optimal flow regimes in the non-dominated set of solutions, with color indicating the relative value of the salmon objective, which generally implies a lower value of the energy objective.

\section{List of Tables}

Table 1. Estimated parameters for relative price model given by Equation 8 


\begin{abstract}
This study identified trade-offs and complementarities between seasonal flow regimes that favor energy producers and those that benefit salmon production in the Tuolumne River, California below Don Pedro Dam. We produced and analyzed a non-dominated set of solutions using two models, one to estimate relative energy value and one to estimate relative salmon production from candidate flow regimes. The analysis suggested that both salmon and energy producers benefitted from pulse-flow releases during hot summer temperatures. However, the timing of an earlier pulse flow differed substantially between optimal flow regimes favoring the two objectives. Earlier flow releases that favored salmon production were allocated in late-winter over an extended period. This broad late-winter pulse inundated floodplain and promoted faster juvenile growth for early cohorts, whereas the later pulse flow mitigated exposure to high river temperatures by later cohorts of juvenile salmon. Optimal minimum flows were also higher in salmon-oriented solutions than in those that favored energy value. Flow releases allocated to maximize energy value occurred in both summer and winter, when cooling and heating increased electricity demand. Intermediate solutions generally allocated steeper and narrow pulses both in summer and during the late-winter, at times mirroring those used by salmon regimes. The steepness of pulse flows to maximize energy was driven primarily by hydraulic capacity (maximum generating flows). In summary, this analysis has improved understanding of the trade-offs and complementarities between seasonal patterns of reservoir releases that favor salmon and those that favor energy value to producers.
\end{abstract}

Keywords: hydropower, marginal cost of electricity, Chinook salmon, multi-objective optimization, NSGA-II, genetic algorithm, Pareto-optimal solutions, quantile model, Oncorhynchus tshawytscha 


\section{INTRODUCTION}

Reservoir flow releases must be allocated over time to meet objectives related to energy production and other water uses. In optimization terms, this is a resource allocation problem. Clearly, water is a scarce resource and competing needs change over time. In multi-objective optimization there is not a single solution, but rather a set of non-dominated solutions that define a Pareto-optimal frontier. Although conflicts over timing and amounts of flow are difficult to resolve, perhaps the least controversial proposition is that releasing water at times that are suboptimal for all parties concerned is something to be avoided. This paper focuses on two important objectives served by reservoir flow releases: Generating hydropower and support for a thriving aquatic ecosystem downstream of dams. The results presented here apply to the Tuolumne River, California. Don Pedro Dam is the main storage project on this tributary of the San Joaquin River.

Multi-objective reservoir optimization has a long history, and this study focuses on two areas that have received less attention: addressing environmental objectives and incorporating seasonal-scale variation in electricity prices. Beginning with environmental objectives, applications considering downstream biota as objectives have been fairly rare (Jager and Smith 2008). Studies have typically settled for allocating flows to meet regulatory constraints rather than maximizing benefits to downstream biota (Jager and Smith 2008). Even those rare cases that considered downstream habitat, relationships were developed over a moderate range of flows (Sale et al. 1982, Cardwell et al. 1996, Jager and Rose 2003). Only recently have the benefits of occasionally inundating shallow, slow habitat for rearing fish have been considered (Jager in review). On the methodological side, the set of Pareto-optimal solutions was until recently estimated by weighting various objectives and solving the problem (e.g., Labadie 2004; 2005). Although solutions thus obtained are good, efficiency is low because a diversity of solutions sets is not maintained during the search (Shukla and Deb 2007). More recently, heuristic methods have been developed for directly solving for the set of non-dominated solutions using genetic algorithms (Deb et al. 2002), and in two cases applied to reservoir operation (Reddi et al. Cioffi and Gallerano 2012).

On the energy side, electricity prices are highly variable and unpredictable, but there are predictable influences at different temporal scales. Harou et al. (2009) review the extensive literature on hydroeconomic modeling, which focuses on maximizing the economic value of water. These models consider some or all of the values associated with urban, agricultural and industrial water demands, hydropower and environmental and recreational uses. On the other hand, the value of downstream biota (for itself, rather than assigning it to a recreational value) is typically overlooked. From a producer's perspective, timing reservoir releases to generate hydroelectric power during peak demand is a critical consideration that determines the economic profitability of hydropower. Variations in demand occur on both within-day and seasonal time scales. Prices are predictably higher during "peak" periods, during daytime hours on weekdays, and lower during off-peak periods that are typically captured by load-following operation. Economic models seeking to forecast short-term, day-ahead price fluctuations have attracted considerable attention because of its relevance for system control, unit commitment, and energy markets. Models typically seek to describe short-term variations through stochastic processes, including, mean-reverting diffusion processes (Clewlow et al. 2000; Deng 2003), autocorrelated 
(GARCH) time-series models (Garcia et al. 2005), and neural-network models (Georgilakis 2007).

Medium and long-term forecasting, which is the scale of interest here, has not received nearly as much attention as short-term forecasting (Hyndman and Fan 2010). Yet, electricity prices vary seasonally as heating and cooling needs increase. In California, air conditioning needs are met by electricity, whereas much of winter heating is supplied by natural gas (Knittel and Roberts 2001). Thus, calendar influences are likely to be important (e.g., Hyndman and Fan 2010). Previous models have found temperature to be an important factor in explaining price fluctuations mediated by load. For example, Ruibal and Mazumdar (2008) found that temperature explained $75 \%$ of short-term variation in load. Temperature also predicted fluctuations in peak demand in South Australia (Hyndman and Fan 2010). Garcia et al. (2011) recently refined their GARCH model by added seasonal components to describe electricity price variation on the Iberian Peninsula. Similarly, seasonal patterns were included in a weekly forecasting model by Zhou and Chan (2009).

The goal of this study is to understand how seasonal allocation patterns that benefit energy producers and those that benefit salmon differ, and where they show similarities. We used genetic algorithm to estimate a Pareto-optimal frontier describing trade-offs in the allocation of seasonal flows to benefit salmon and energy producers. Energy value derived from reservoir releases was estimated by an empirical model describing seasonal variation in electricity prices.

To represent benefits to salmon, we relied on the Quantus model, which was previously used to optimize flows for Chinook salmon (Oncorhynchus tshawytcha) in a Central Valley river (Jager in review). Salmon production is an environmental objective that is important in many coastal rivers, and we used the Tuolumne River, located in the Central Valley of California as a case study for this analysis. Quantus was developed as an effort to simplify an earlier, more-complex spatially explicit and individual based population model linking fish growth, development, reproduction, movement, and survival to dynamic flow- and temperature-driven changes in physical river habitat (Jager et al. 1997; Jager and Rose 2003). Two main advantages over more complex models are that it represents the effects of floodplain inundation on juvenile salmon growth and is much faster to run than spatially explicit and individual-based population models. Thus, three features of the approach here should enhance efficiency in discovering a Paretooptimal frontier: 1) use of a simple salmon model, 2) use of a low-dimensional parametric model to describe seasonal flow regimes, and 3 ) use of the NSGA-II method to discover nondominated solutions. 


\section{METHODS}

The optimization approach used here allows the user to discover a set of flow regimes that are close to Pareto-optimal with respect to two objectives: maximizing simulated salmon production and maximizing relative energy value. Jager (in review) developed a quantile-based salmon recruitment model, Quantus. For a given seasonal flow regime and total annual flow, Quantus returns the proportion of Chinook salmon eggs surviving to migrate to sea. To estimate the effect of flow on energy value, we developed an empirical model for seasonal variation in marginal electricity price as a function of temperature. Models to describe both salmon and energy value of proposed seasonal flow regimes are described in sections below.

\subsection{CLIMATE DRIVERS AND PHYSICAL HABITAT}

River habitat in this model consists of longitudinal representation of three drivers, flow, air temperature, and dam-release temperature. Flow is the decision variable in the optimization. Water temperature is derived from equilibration between dam-release temperature and air temperature as a function of flow (Jager in review). Inundation of floodplain areas begins in the Tuolumne River when flows exceed approximately $30 \mathrm{cms}$ based on aerial photographs taken between 1988 through 1995 at flows ranging from 2.83 to $237.9 \mathrm{cms}$ (Gard 2008).

The flow-regime generator begins with a total annual flow, which is expressed as average flow, $Q_{a v g}$, in cms. This analysis was conducted for an annual flow of $0.631 \mathrm{~km}^{3}$ (511 TAF). If allocated uniformly throughout a year, this would correspond with a constant flow of $20 \mathrm{cms}$ (cubic meters per second). For reference, the quartiles of regulated flows in the Tuolumne River between 1971 and 1997 were $25 \% \leq 6.4$ $\mathrm{cms}, 50 \% \leq 12.0 \mathrm{cms}$, and $75 \% \leq 36.5 \mathrm{cms}$ (Brown and Ford 2002). Unimpaired flows were historically much higher, with a median daily average flow of $33.6 \mathrm{cms}$ (Brown and Ford 2002).

Generated flow regimes, $Q(\mathrm{t})$, were represented by a parametric model mainly to reduce the number of decision variables in the optimization problem and to facilitate interpretation of results. Our goal is to understand how seasonal allocation patterns that benefit energy producers and those that benefit salmon differ and where they show similarities.

The flow model consist of three parts: a minimum flow, $Q_{\text {min }}$, and two flow pulses, one in fall and one in spring (Equations 1 and 2). Each pulse was represented by a uni-modal pattern of flows and four parameters of the double Weibull distribution. The fall pulse begins on Julian date FallJday and extends FallDur days. The spring pulse begins on day SprJday and extends SprDur days. Input parameters, provided in Julian dates, are converted by transformation $W$ to water-year dates that begin on Julian day 274. Parameters FallK and SprK control how steeply the flow pulses increase and decrease ( $k$ in Equation 3). Weibull location parameter, $t m$, which shifts the distribution forward or back in time, is set to zero (beginning of the water year) for the putative fall pulse and optimized across values less than SprJday for the spring pulse. In the equations below, Jday, refers to either the start of the spring or fall pulse. 


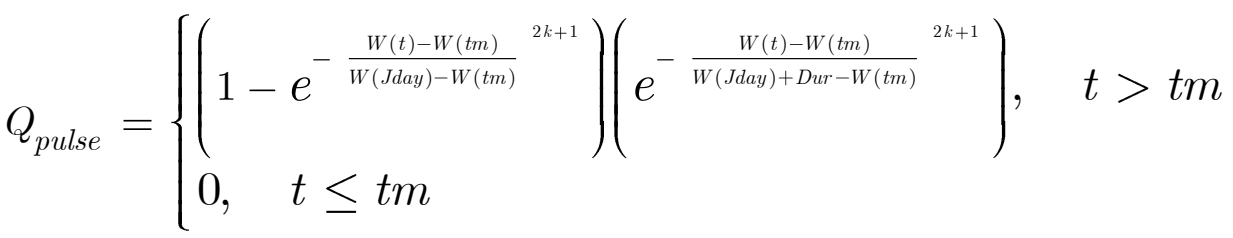

$$
\begin{aligned}
& f(t)=Q_{\text {min }}+Q_{\text {pulse,fall }}+Q_{\text {pulse }, \text { spr }} \\
& Q(t)=f(t)\left(\frac{T \cdot Q_{a v g}}{\sum_{T} f(t)}\right)
\end{aligned}
$$

\subsection{HYDROPOWER VALUE}

We developed an empirical model that describes seasonal variation in hydropower value. Within-day variation, which is clearly an important economic driver, is not considered as part of the seasonal allocation of flows, but would be a next step in refining the flow regime.

Two main influences on daily average energy value at a particular hydropower project are the amount of water generating electricity and seasonal influences on the value of electricity. Only flows up to the hydraulic capacity through the four turbines, $Q_{\text {gen }}<=Q_{\text {spill }},=155.76 \mathrm{cms}$, generate electricity. It is rare for spill to occur at the Don Pedro (TID/MID 2011) because the storage capacity of Don Pedro exceeds the annual reservoir inflows in most years. Furthermore, a significant fraction is diverted to support agriculture in the Central Valley. Thus, spill under current operations is rare for this particular project, but it is likely to be important for smaller projects.

\subsection{ELECTRICITY GENERATION}

Daily electricity generation is currently modeled empirically using top-down relationships derived from the US Energy Information Agency. In future, this approach will be compared with, and replaced by bottom-up estimates of turbine deployment and efficiency.

Top-down method.- Jager and Sale (2006) fitted a linear relationship between daily generation and flow, based on annual generation data and daily average flows $(\mathrm{cms})$ during the period 1970-2003. The linear relationship $G_{t}(M W h)=810.43+6.265 Q_{g e n}$ explained $77 \%$ of variation in energy generation, in spite of presumed variation in reservoir storage and hydraulic head. Under optimal conditions, the maximum output is $203 \mathrm{MW}$ (TID/MID 2011). In the daily optimization model, we estimated energy using Equation 4, where maximum generating capacity, $G_{c a p}=203 \mathrm{MW}$ x $24 \mathrm{~h}$.

$$
G_{t}(M W h)=\left\{\begin{array}{l}
b_{0}+b_{1} Q_{g e n}, \quad Q_{g e n} \leq Q_{c a p}, \\
G_{c a p}, \quad \text { otherwise }
\end{array}\right.
$$

Bottom-up method.-An additional consideration is the loss of efficiency when turbines are deployed using sub-optimal flows. The efficiency and power generated by hydroelectric facilities is highest when the flow released through each turbine results in peak efficiency. Power generation is a product of 
hydraulic head, generating flow, and efficiency (Mesa Associates \& ORNL 2011). Consequently, to estimate the variation in generation, we need not only the proposed seasonal flow regime, but also seasonal variation in head, and generation efficiency. At this point, the relationship between efficiency and flow has been quantified at three different levels of head (Figure 1a), and what remains to be done in future is to describe predictable seasonal variation in head (Figure 1b).
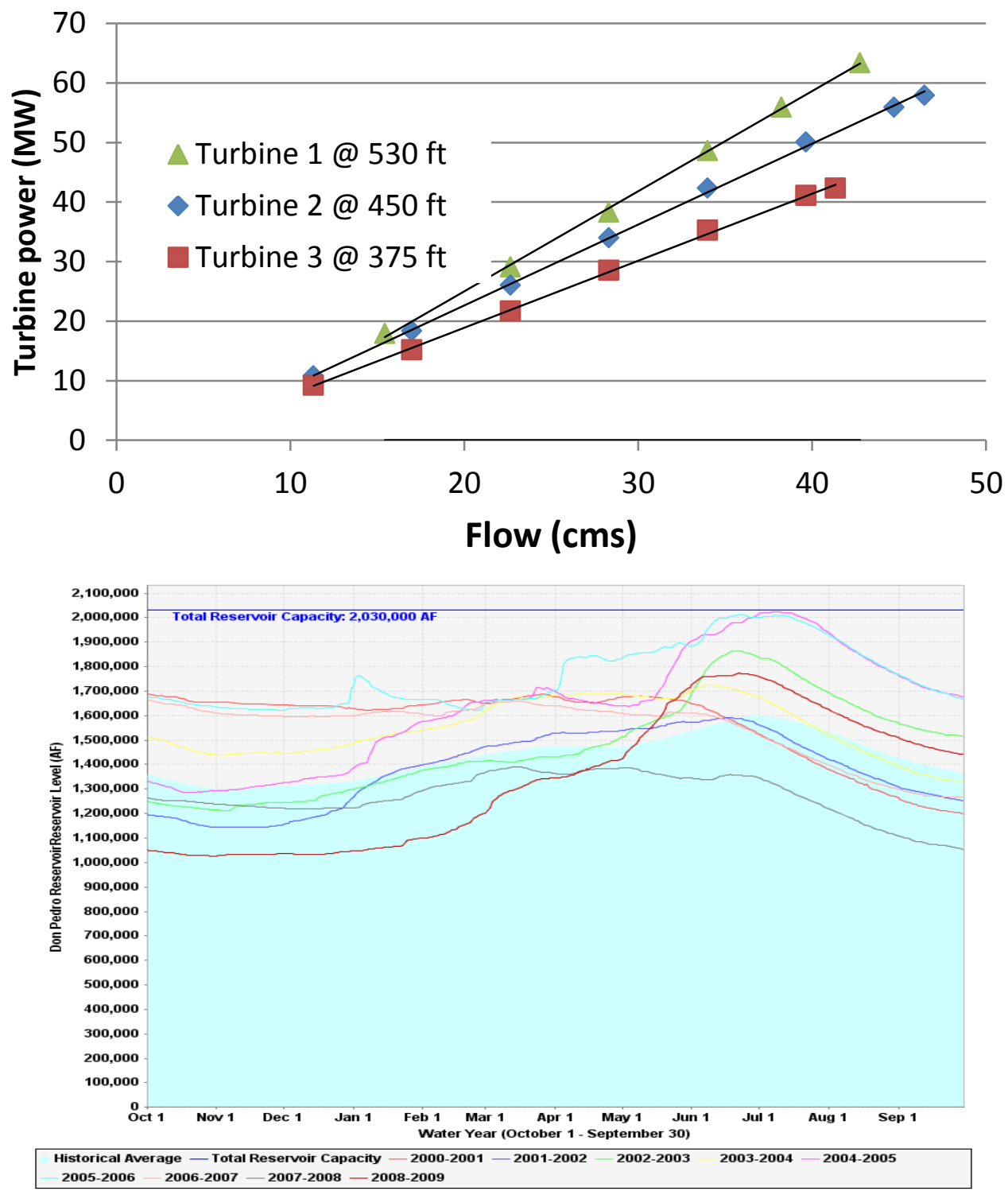

Figure 1. Two relationships that describe seasonal influences on power generation: (top) turbine efficiency, power generation vs. flow; (bottom) predictable seasonal variation in head, as determined by reservoir elevation (Source of bottom graph: Stillwater Sciences 2011).

The Don Pedro Dam has 4 Francis turbines, three of which generate $G_{c l}=55 \mathrm{MW}$ and one $G_{c 2}=38 \mathrm{MW}$ at peak hydraulic capacity (TID/MID 2011). The estimated hydraulic capacity estimated for the larger 
turbines was $37.19 \mathrm{cms}$, and by difference from a total of $Q_{\text {spill }}=155.76 \mathrm{cms}$ (TID/MID 2011), the smaller turbine generates using flows up to $Q_{c 2}=44.22 \mathrm{cms}$.

An analysis of efficiency ratings for the three larger turbines was presented in a pre-application document (TID/MID 2011) for three different values of net head. We fitted relationships between power generation and flow for three identical turbines (Figure 1a). The relationship with the maximum head (176 m), $g(x)$ in Equation 5, has parameters $c_{0}=8.625$ and $c_{1}=1.681$. The fourth turbine's curve can be assumed to be the same, but with a lower hydraulic capacity, $Q_{c 2}$. Beyond peak capacity, generation can be assumed to be flat, as no decline was evident in the testing. Total power on each day, $t$, is given by Equation 5, where the maximum number of larger-capacity turbines, $k_{1}$, is first fully employed. Allocation of remaining flow depends on whether it exceeds the capacity of smaller turbines. If so, another large turbine is first engaged and the remainder allocated to the smaller turbine. If not, the remainder is used to generate by engaging the smaller-capacity turbine, up to its maximum capacity.

$$
\begin{aligned}
& G_{t}(M W h)=24\left[k_{1} g\left(Q_{c}\right)+g\left(\min \left\{\left(Q_{\text {spill }}-k_{1} Q_{c 1}\right), 0, k_{2} Q_{c 2}\right\}\right)\right], \sup \left\{k_{1} \in[0,3] \ni k_{1} Q_{c} \leq Q_{\text {spill }}\right\}, \\
& \text { where } g(x)=\left\{\begin{array}{l}
c_{0}+c_{1} x, x>0 \\
0, \quad \text { otherwise }
\end{array}\right.
\end{aligned}
$$

Seasonal value.-Each day's relative energy value is estimated as the product of electricity generation, $G_{t}$ $(\mathrm{MWh})$ and the relative seasonal deviation in marginal price at the time of generation, $P_{t}$ in $\$ / \mathrm{MWh}$. To scale the energy objective on $[0,1]$, because we are only interested in relative profit, we keep units of fraction of $G_{c a p}$ x relative price (Equation 6), where the price deviations, having been modeled by a generalized logistic function, are on a $0-1$ scale.

$$
\text { EnergyValue }=\frac{\sum_{t=1}^{365} G_{t} P_{t}}{G_{c a p}}
$$

We developed an empirical model to describe predictable patterns in temporal variation in marginal cost of electricity in the California electricity market relevant to the Don Pedro project. Two modeling objectives were (1) to characterize influences of temperature and time components on the mean and variance in marginal cost of electricity (MCE), and (2) to estimate relative seasonal fluctuations in MCE for use in optimizing flow releases. We obtained historical price data for the period 2003-2008 from the California ISO site (http://oasis.caiso.com/mrtuoasis/?doframe $=$ true $\&$ serverurl $=$ http $\% 3 \mathrm{a} \% 2 \mathrm{f} \% 2 \mathrm{ffrptp} 09$. oa.caiso.com $\% 3 \mathrm{a} 8000 \&$ volume=OASIS $)$. We avoided earlier data that were influenced by the transition to market deregulation in 2000 (Knittel and Roberts 2001).

Climate can potentially influence electricity demand through temperature, which determines the need for cooling. In a previous study, forecasts of temperature and demographic increases were used to forecast long-term electricity demand in South Australia (Hyndman and Fan 2010). Because temperature seems a more natural or direct influence on electricity use than day of year, we included this as a predictor of MCE. We obtained historical daily climate data for the period 2003-2008 from DAYMET (http://www.daymet.org/), which is maintained at Oak Ridge National Laboratory.

In a two-stage modeling approach, we first removed year-to-year variation because the optimization model is concerned only with seasonal variation. I focused on modeling residuals, $P_{t}$, from year effects 
using variables related to demand and short-term lagged prices as predictors (Equation 7). These residuals can be thought of as deviations from mean-average price.

$$
P_{t}=\mathrm{MCE}_{t}-\left[\alpha_{0}+\sum_{t} \alpha_{t} I_{s} Y_{e a r}\right]
$$

Demand-related variables daily average temperature, Tavg, and Tdis, a discomfort index, calculated as zero for Tavg, in the range 18 to $24^{\circ} \mathrm{C}$ and the minimum deviation from this comfort range for temperatures outside this comfort zone. Autocorrelation (ACF) plots were used to assess residual autocorrelation, and based on this, we fitted a model using 1-day lagged values of Tavg and Tdis (Equation 8). This corresponds with the reasonable assumption that prices are based on lagged information. Parameters of this generalized logistic model were fitted using non-linear least squares as implemented by the 'nlme' package in R.

$$
\begin{aligned}
& P_{t}=R_{\min }+\left(R_{\max }-R_{\min }\right) P_{r e l, t}, \\
& P_{r e l, t}=\frac{\exp \left(y_{t}\right)}{1+\exp \left(y_{t}\right)}, \text { where } y_{t}=\beta_{0}+\beta_{1} y_{t-1}+\beta_{2} \text { Tavg }_{t-1} \beta_{2} \text { Tdis }_{t-1}+\varepsilon
\end{aligned}
$$

On an annual basis, we evaluated the producer benefit from each annual flow regime, $V_{E}$, as the sum over days of the product of electricity generation and the relative value of electricity. Relative price deviations were scaled on $[0,1]$.

\subsection{ECOLOGICAL VALUE}

Quantus tracks the development, growth, and survival of fall Chinook salmon by representing quantiles of the temporal and spatial distribution of redds (nests). These space-time quantile-cohorts are then tracked and encounter seasonal changes in flow and water temperature at different developmental stages and sizes. To be considered successful, cohorts must grow to a minimum size threshold and successfully travel downstream to the confluence. Overall production is quantile-weighted survival from egg to smolt.

Temporal variation in the distribution of spawning dates for the fall run is represented by a triangular distribution beginning October $1^{\text {st }}$, peaking on October $27^{\text {th }}$, and ending on December $22^{\text {nd }}$. The spatial distribution of initial redds was represented by a triangular distribution over the upper portion of the river to Lsegsp $=40.5 \mathrm{rkm}$ as described in Jager et al. 1997). The $5^{\text {th }}, 25^{\text {th }}, 50^{\text {th }}, 75^{\text {th }}$, and $95^{\text {th }}$ quantiles of 10,000 draws of each is used to characterize the distribution of redds in time and space, independently.

For each quantile-cohort, development through the egg and alevin life stages proceeds based on accumulated degree days. Incubation survival was modeled as a function of temperature. Fry emerge from the gravel at a size of $35 \mathrm{~mm}$ after accumulating 895.8 degree days $\left({ }^{\circ} \mathrm{C}\right.$ ) (Murray and McPhail 1988). From this point forward, each quantile's growth, movement, and survival is tracked. The migration process starts at the initial redd location of the quantile-cohort. Once a quantile cohort reaches a specified fraction of minimum smolt size, downstream migration begins, with the rate depending on juvenile size, flow, and temperature.

Growth is simulated for each quantile cohort from emergence until fry become smolt and leave the tributary. The simulated growth rate of juveniles belonging to a quantile cohort depends on temperature, fish size, and the amount of inundated floodplain (a function of flow). When flows are high enough to inundate floodplain, simulated growth is enhanced because of increased prey availability. Ration was 
increased from a specified minimum to one as the antecedent area of floodplain inundated increased (Sommer et al. 2001; Jeffres et al. 2008).

Survival is estimated for two periods, incubation and the juvenile rearing period. Values are calculated for cohorts each space-time quantile and depend on the unique temperatures and growth opportunities that they experience. Once the cohort reaches the smolt life stage and migrates to the mainstem, calculation of survival ends. Fry survival for a given quantile cohort continues to decline until that day in spring when the cohort attains a length of $75 \mathrm{~mm}$ and reaches the confluence with the mainstem San Joaquin River. Components of survival that affect different life stages are described in Jager (in review).

Juvenile production, the endpoint of Quantus is defined by thresholds in fish size and position. At the end of the simulation, survival through these periods is used to reweight quantiles when calculating the number of juveniles that survive to migrate to sea. Thus, the final proportion of eggs, $E_{f r}$, surviving to migrate as smolts is a convolution of the probability covered by each space-time quantile, $\mathrm{f}_{\mathrm{qs}}$ qt and its egg-smolt survival, $S_{q s, q}$, (Equation 9). This is used as the salmon objective in the optimization described in the next section.

$$
\text { Salmon Value }=V_{s}=\sum_{q s} \sum_{q t} f_{q s, q t} S_{q s, q t}
$$

\subsection{FLOW OPTIMIZATION}

The optimization problem solved here is designed to shape seasonal flows to maximize both value to salmon and value to energy producers by directly minimizing the non-domination rank (i.e., number of previous solutions with higher values with respect to at least one of the two objectives, $V_{E}$ and $V_{s}$ in Equations 8 and 9).

$$
\begin{aligned}
& \min \operatorname{Rank}\left\{V_{S}(x), V_{E}(x)\right\}, \\
& \text { subject to: } \\
& x_{i}^{L} \leq x_{i} \leq x_{i}^{U} \text { :integer, } i=1, \ldots n \\
& x=\left[x_{1}, x_{2}, \ldots, x_{n}\right]
\end{aligned}
$$

The decision variables were $n=8$ integer parameters describing flow regime, including scaled minimum flow, Qmin, and seven parameters that control the seasonal timing and duration of two pulses in flow. Qmin was constrained to be greater than $1.42 \mathrm{cms}$.

Two approaches to multi-criterion optimization are to solve for a weighted objective, where different weights (summing to 1) are assigned to different objectives, or to directly seek solutions along a Pareto optimal front by minimizing domination rank of solutions. We implemented the latter approach, using the Non-dominated Sorting Genetic Algorithm II (NSGA-II), a multi-objective evolutionary optimization algorithm implemented in R (Deb et al. 2002) to solve for the values of $x$. The truncation approach of Deep et al. (2009) was used to make the algorithm suitable for integer decision variables. Solutions to optimizations with $100 \%$ weight assigned to salmon were compared with solutions on the non-dominated front to assess the quality of solutions. 
Evolutionary or genetic algorithms borrow concepts from evolution. A sequence of generations is simulated for a virtual population of individuals. The 'genotype' of each individual has values (i.e., alleles) corresponding to integer values of parameter vector $P q=\{$ Qmin, FallJday, FallJdel, SprJday, SprJdel, Falltmin, FallK, and SprK\} that describe the flow regime. Each genotype is associated with a 'fitness' that corresponds with the objective (i.e., salmon production). As with other heuristic global search methods, genetic algorithms have a deterministic and a random component. In the process of evolution, natural selection is deterministic, whereas mutation and sexual recombination are random features that provide the capability to generate new combinations and consequently escape from local optima. Parameters controlling the distributions used to draw subsequent generations were, $\mathrm{cprob}=0.8$, cdist $=5$, mprob $=0.1$, mdist $=10$. All flow parameters were treated as integer decision variables $(Q m i n$ scaled by 1000).

The maximum number of generations was set to 1,000 and population size to 100. Results are presented for an average flow of $20 \mathrm{cms}$. Convergence was assumed to occur after 20 generations with no change in the solution, within a specified solution tolerance of $10^{-5}$ for the weighted objective. For the solution with $100 \%$ weight assigned to salmon, convergence can be evaluated by comparing three solutions with the highest salmon objective (Figure 2).

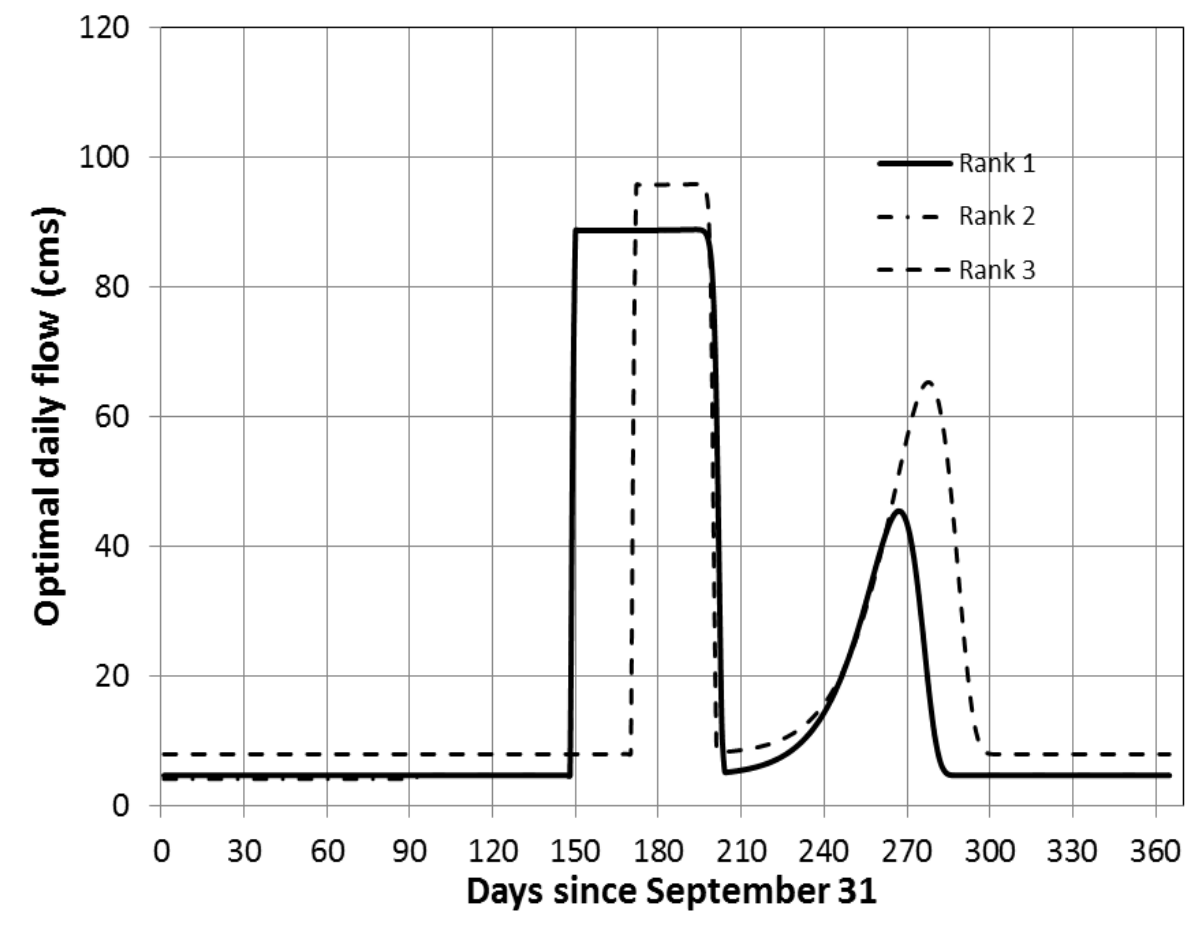

Figure 2. Optimal flow regimes to meet the salmon production objective. These flow regimes allocated total annual flows of $0.632 \mathrm{~km}^{3}$ and were obtained using a single-objective method, with a weight of one assigned to the salmon objective. Results are shown for three different initial seeds, two of which overlap substantially. 


\section{RESULTS}

Below, we describe results of our energy value modeling and optimization results. Results of modeling salmon production can be found in Jager (in review) and are not repeated here.

\subsection{HYDROPOWER VALUE}

Seasonal relative marginal prices, as represented by the model fitted in Equation 8), showed a large peak in summer and a secondary, lower peak in winter (Figure 3). Parameters are listed in Table 1 below. Although model and its coefficients were highly significant, the correlation between predicted and observed values remained fairly low, 0.316 . The residual standard error was 0.1268 on 2,530 degrees of freedom. Based on comparisons of AICc, removals of predictors did not result in a more-parsimonious explanatory model. Residual analysis showed that the majority of autocorrelation was removed by this AR-1 model using lagged predictors.

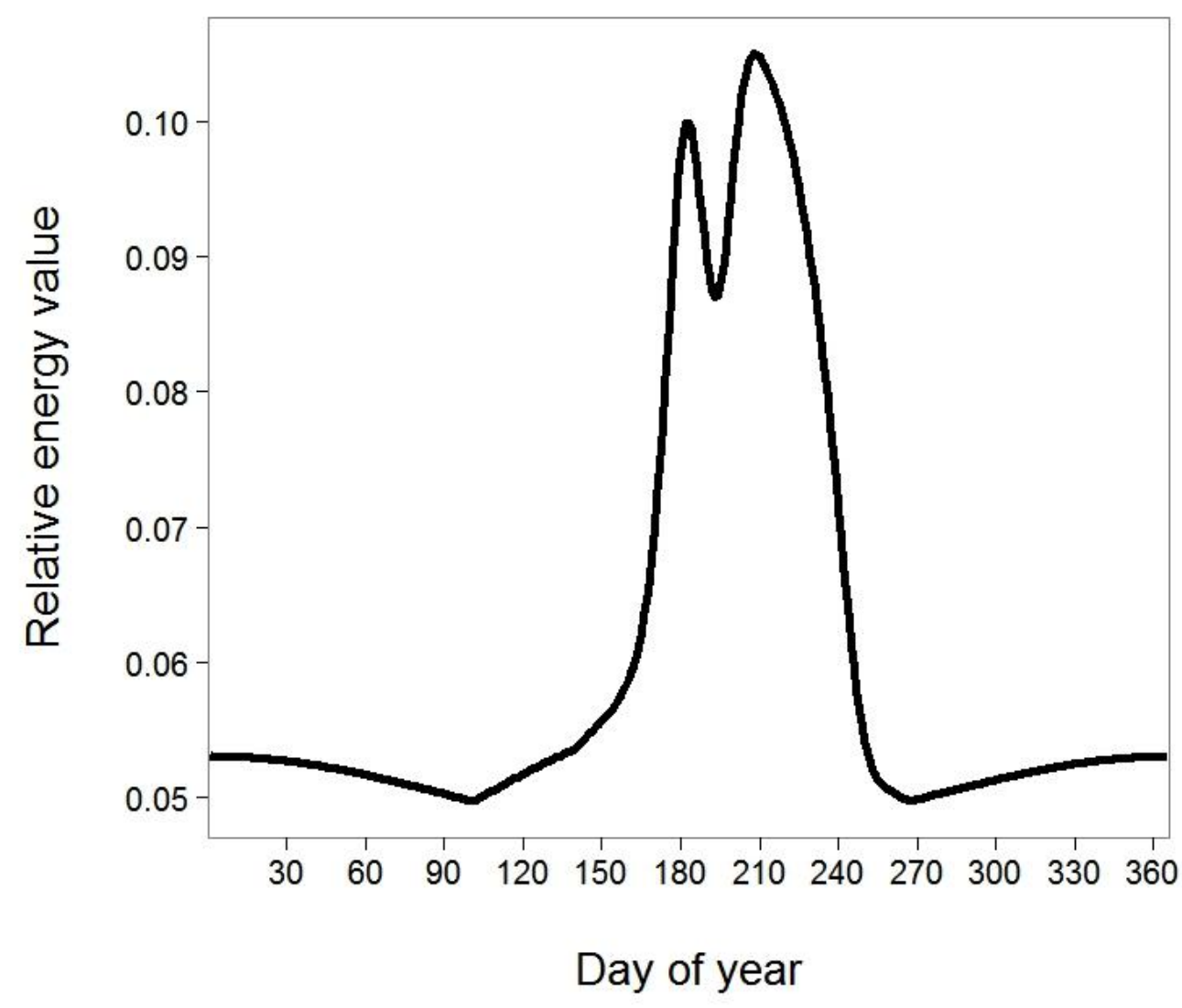

Figure 3. Seasonal patterns in relative marginal energy value, based on fitted model. 
Table 1. Estimated parameters for relative price model given by Equation 8.

\begin{tabular}{|l|l|l|l|}
\hline Parameter & Estimate & $\mathrm{SE}$ & $\mathrm{T}$ and $\operatorname{Pr}(>|\mathrm{T}|)$ \\
\hline$\beta_{0}$ & -1.1202 & 0.0686 & $-16.324(<0.00001)$ \\
\hline$\beta_{1}$ & 0.00327 & 0.0002 & $15.844(<0.00001)$ \\
\hline$\beta_{2}$ & 0.01323 & 0.0029 & $4.509(<0.00001)$ \\
\hline$\beta_{3}$ & 0.01908 & 0.0050 & $3.806(0.00014)$ \\
\hline
\end{tabular}

\subsection{OPTIMAL SEASONAL RELEASE SCHEDULE}

We identified a set of seasonal patterns of reservoir releases representing 100 non-dominated solutions among those evaluated by NSGA-II. These solutions fall along a gradient from maximizing the production of Chinook salmon downstream to maximizing energy value (Figure 4).

Comparing flow regimes along the continuum from maximizing energy value vs. salmon production we see both similarities and differences (Figures 4 and 5). The optimal flow regime that maximized only salmon production was characterized by a steep spring pulse flow corresponding with minimum and maximum temperatures (Figures 4 and 5). A sampling of flow regimes from the non-dominated set, ranging from those with higher values for energy objectives to those with higher values for salmon objective, reveals the gradation of change in suggested patterns of seasonal flow release indicated by this analysis (Figures 4 and 5). 


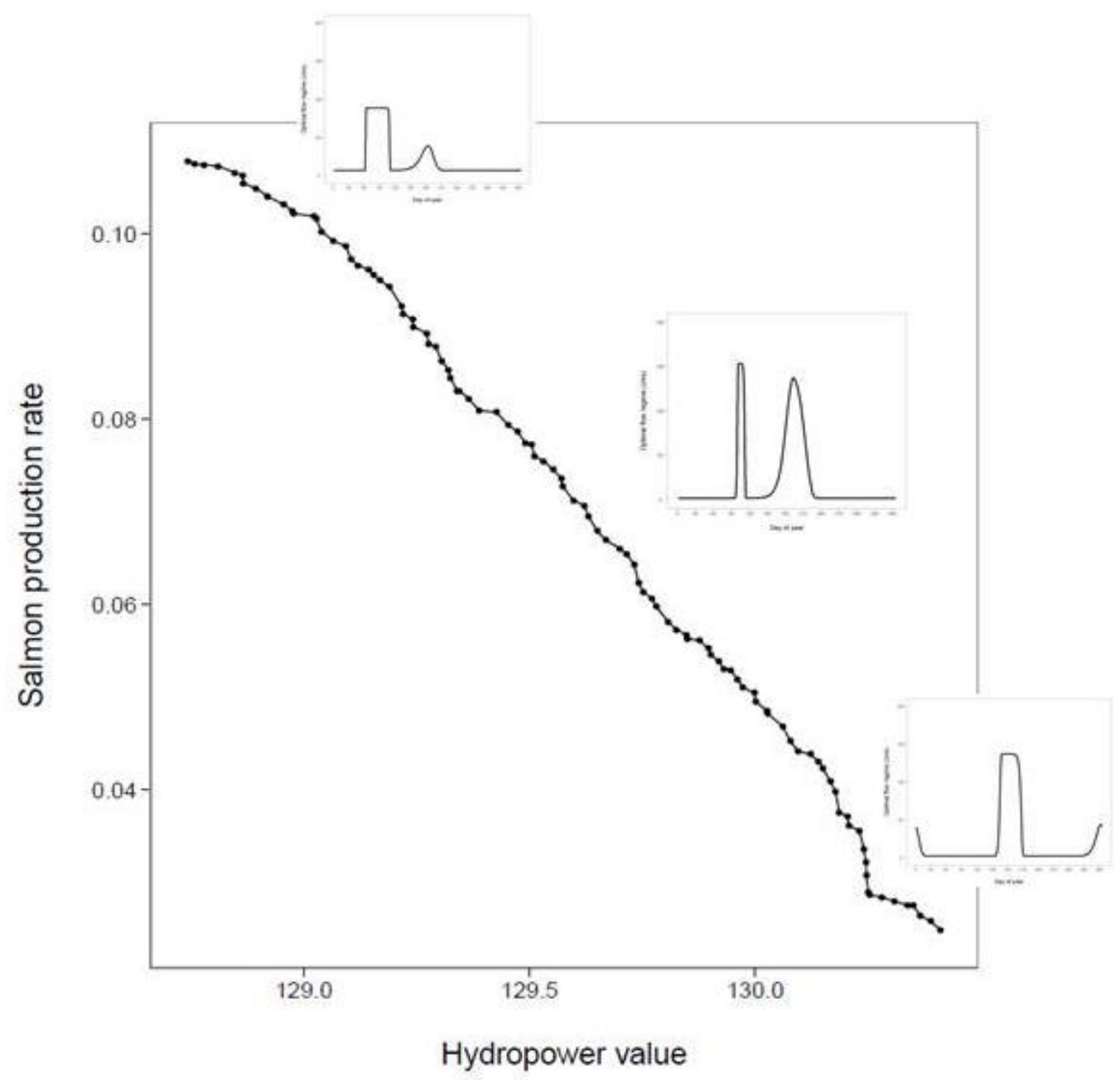

Figure 4. Frontier of non-dominated solutions showing the shift in seasonal flow regimes favoring model-simulated salmon production and those favoring energy value. Three examples of optimal flow regimes are illustrated above their positions along the frontier. 


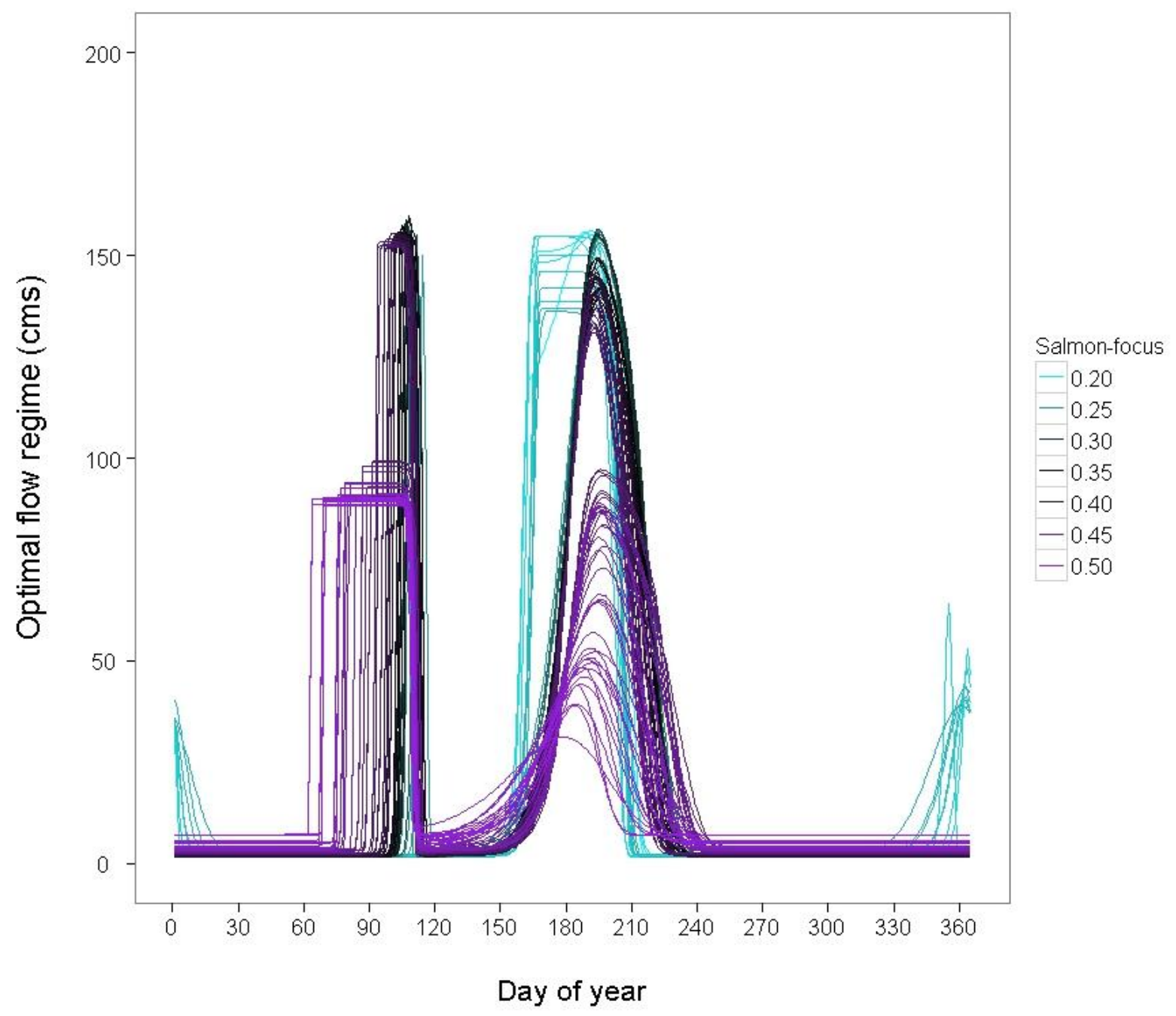

Figure 5. Optimal flow regimes in the non-dominated set of solutions, with color indicating the relative value of the salmon objective, which generally implies a lower value of the energy objective. 


\section{DISCUSSION}

This analysis revealed one interesting correspondence between allocating pulse flows to favor salmon production vs. energy value. Overall, the set of 100 non-dominated solutions included none at the extremes with no salmon production or no energy value, and we obtained extremes through separate single-objective (weighted with weight $=0$ and 1 ) optimizations. However, we compared extremes that were represented in the set. These revealed some commonalities and some differences between salmon- and energy-favoring solutions. Specifically, both salmon and energy producers benefitted from releases during high late-spring and early-summer temperatures (Figure 3). For energy producers, later releases generate electricity when air conditioners are most required. For salmon, late-exiting cohorts are better protected from high water temperatures during out-migration. One might expect energy-focused solutions to call for these pulses later in summer than those required by salmon, but these results, if anything, show later pulses in the solutions favoring salmon production (Figure 5). We would not expect many juveniles to exit as late as the end of June, unless they were members of the late-fall run (see Jager and Rose 2003 for discussion of maximizing life history diversity in salmon).

The analysis revealed trade-offs between objectives primarily in the allocation of a second, earlier pulse flow. Energy-favoring solutions included a pulse flow in winter, whereas salmonfavoring solutions shifted this to produce a broad floodplain-inundating pulse in early spring. Evaluation of different hydrologic years indicated that floodplain-inundating flows were not optimal in drier years (Jager in review). Interestingly, the intermediate solutions produced much narrower and steeper floodplain-inundating pulses. This might raise concerns about stranding juveniles (Sommer et al. 2005; Grand et al. 2006). Representing stranding might help to refine the shape of the descending limb for high pulse flows, which was quite steep in these solutions.

This was a first step toward incorporating economic objectives, as suggested by Harou et al. (2012). Here, we represented energy value, but ecological value was not addressed specifically. Although we successfully represented seasonal price variation, uncertainty in marginal prices has not been incorporated, nor is it clear how we can compare the relative credibility's of the two model-derived objectives. In particular, the relative price model had fairly low inherent predictive capability, and it would not be particularly difficult to use a risk-based formulation for the energy objective. We have not yet formally explored parameter sensitivities of these results. For example, we observed that the maximum hydraulic capacity (Qspill) has a large influence on the steepness of energy-favoring flow pulses. In future, turbine efficiency could be considered as well, and this would require combining the influences of generation and relative price.

The prospects for assessing the economic value of, and incorporating uncertainties associated with, salmon production are bleaker. Previous efforts to compare model results against salmon outmigrants counts using rotary-screw traps have not been particularly successful, in part because counts are confounded with flow (Jager and Sale 2006). In future, a sensitivity analysis of parameters can help to assess these influences. The ecological value of salmon, which was estimated by Loomis and White (1996) to be range from $\$ 31$ to $\$ 88$ in 1993 dollars, can also be incorporated in future.

In summary, despite the uncertainty in model-estimated objectives, this analysis has led to an improved understanding of the trade-offs and complementarities between seasonal patterns of reservoir releases that favor salmon and those that favor energy value to producers. 


\section{ACKNOWLEDGEMENTS}

This research was supported by the United States Department of Energy's (DOE) Energy

Efficiency and Renewable Energy Office, Wind and Water Power Technologies Program and conducted by Oak Ridge National Laboratory (ORNL), which is managed by UT-Battelle, LLC, for the DOE under contract DE-AC05-00OR22725. We appreciate the advice of Dr. Jitendra Kumar for implementing the NSCA-II optimization. 


\section{LITERATURE CITED}

Brown LR and T Ford (2002) Effects of flow on the fish communities of a regulated California river: Implications for managing native fishes. River Research and Applications 18: 331444

Cioffi, F and F Gallerano (2012) Multi-objective analysis of dam release flows in rivers downstream from hydropower reservoirs. Applied Mathematical Modelling 36:28682887.

Deb, K., A Pratap, S Agarwal, and T Meyarivan (2002) A fast and elitist multiobjective genetic algorithm: NSGA-II. IEEE Transactions on Evolutionary Computation 6:182-197.

Deep, K., K. P. Singh, L. Kansal, and C. Mohan (2009) A real coded genetic algorithm for solving integer and mixed integer optimization problems. Applied Mathematics and Computation 212:505-518.

Gard M (2008) Flow-overbank inundation relationship for potential fall-run Chinook salmon and steelhead/rainbow trout juvenile outmigration habitat in the Tuolumne River. Exhibit No. FWS-82. 15 pp.

Gibbs, MS, HR Maier, and GC Dandy (2011) Relationship between problem characteristics and the optimal number of genetic algorithm generations. Engineering Optimization 43(4): 349-376.

Grand, T, Railsback S, Hayse J, and K Lagory (2006) A physical habitat model for predicting the effects of flow fluctuations in nursery habitats of the endangered Colorado pikeminnow (Ptychocheilus lucius). River Research and Applications 22: 1125-1142.

Harou, JJ, M Pulido-Velazquez, DE Rosenberg, J Medellin-Azuara, JR Lund, and RE Howitt (2009) Hydro-economic models: Concepts, design, applications, and future prospects. Journal of Hydrology 375: 627-643.

Jager, HI, Cardwell HE, Sale MJ, Bevelhimer MS, Coutant CC and W VanWinkle (1997) Modelling the linkages between flow management and salmon recruitment in rivers. Ecological Modelling, 103:171-191.

Jager, HI and KA Rose (2003) Designing optimal flow patterns for fall Chinook salmon in a Central Valley, California River. North American Journal of Fisheries Management, 23:1-21.

Jager, HI and MJ Sale (2006) Functional Comparison between Predictions of a Chinook Salmon Model and Monitoring Data in the Tuolumne River, California. California Energy Commission, PIER Energy-Related Environmental Research. CEC-500-2006-098.

Jager, HI and BT Smith (2008) Sustainable reservoir operation: Can we generate hydropower and preserve ecosystem values? River Research and Applications 24: 340-352. 
Jager, HI. In review. Shaping pulse flows for salmon. Ecological Applications.

Jeffres CA, Opperman JJ and PB Moyle (2008) Ephemeral floodplain habitats provide best growth conditions for juvenile Chinook salmon in a California river. Environmental Biology of Fishes, 83:449-458.

Knittel, CR and MR Roberts (2001) An empirical examination of deregulated electricity prices. PWP-087.

Knittel, CR (2006) The adoption of state electricity regulation: The role of interest groups. The Journal of Industrial Economics LIV(2): 0022-1821.

Labadie, JW (2004) Optimal operation of multireservoir systems: State-of-the-art review. Journal of Water Resources Planning and Management-ASCE 130:93-111.

Labadie, JW (2005) Closure to "Optimal operation of multireservoir systems: State-of-the-art review" by John W. Labadie. Journal of Water Resources Planning and ManagementASCE 131:407-408.

Lettenmaier DP and TY Gan (1990) Hydrologic sensitivities of the Sacramento-San Joaquin River basin, California, to global warming. Water Resources Research 26: 69-86.

Loomis, J and DS White (1996) Economic benefits of rare and endangered species: summary and meta-analysis. Ecological Economics 197-206.

Mesa Associates, Inc. and Oak Ridge National Laboratory (2011) Best Practice Catalog Francis Turbine. Report to USDOE, Hydropower Assessment Program.

Murray CB and JD McPhail (1988) Effect of incubation temperature on the development of five species of Pacific salmon (Oncorhynchus) embryos and alevins. Can. J. Zool., 66:266273.

Ruibal CM and M Mazumdar (2008) Forecasting the mean and the variance of electricity prices in deregulated markets. Transactions on Power Systems 23: 25-32.

Sale, MJ, JE Downey Brill, and EH Edwin (1982) An Approach to Optimizing Reservoir Operation for Downstream Aquatic Resources. Water Resources Research 18:705-715.

Shukla, PK and K Deb (2007) On finding multiple Pareto-optimal solutions using classical and evolutionary generating methods. European Journal of Operational Research 181:16301652.

Sommer TR, Nobriga ML, Harrell WC, Batham, and WJ Kimmerer (2001) Floodplain rearing of juvenile Chinook salmon: evidence of enhanced growth and survival. Canadian Journal of Fisheries and Aquatic Sciences 58:325-333.

Sommer TR, Harrell WC and ML Nobriga (2005) Habitat use and stranding risk of juvenile Chinook salmon on a seasonal floodplain. North American Journal of Fisheries Management 25:1493-1504. 
Stillwater Sciences (2011) Tuolumne River water temperature modeling study. Final Report. Prepared by Stillwater Sciences, Sciences, Berkeley, California for Turlock Irrigation District and Modesto Irrigation District, California. March.

TID/MID (Turlock Irrigation District and Modesto Irrigation District) (2011) Don Pedro Project FERC No. 2299. Pre-application Document. Volume I.

Zi Z and WK Chan (2009) Reducing electricity price forecasting error using seasonality and higher-order crossing information. IEEE Transactions on Power Systems 24: 1126-1135. 